\title{
PRODUÇÃO DE PÓLEN APÍCOLA COM COLETOR NOS HORARIOS DE DISPONIBILIDADE DE ALIMENTO NO PICO DA FLORADA DA BRACATINGA (Mimosa scabrella)
}

\section{PRODUCTION OF BEE POLLEN USING POLLEN COLLECTORS IN THE TIMETABLE OF FOOD AVAILABILITY IN THE TOP OF BRACATINGA'S BLOOM (Mimosa scabrella)}

\author{
Joelma MOURA 1 \\ Adhemar PEGORARO²
}

\begin{abstract}
RESUMO
$\mathrm{Na}$ Cidade de Mandirituba, PR (no sul do Brasil), foi analisada a produção de pólen apícola no pico da florada de bracatinga através do uso de coletores de pólen em sistema não-contínuo durante nove dias, de 03 a 24 de agosto de 2005 . O objetivo deste estudo foi observar o período do dia que ocorre esta coleta pelas abelhas Apis mellifera L. associada á temperatura ambiente e umidade relativa no ar. Dessa foram utilizadas 13 colméias tipo americana, com abelhas africanizadas contendo rainhas com nove meses de idade $e$ predominantemente com florada de bracatinga. A produção média de pólen observada nas colônias foi de $42,70 \pm 24,34 \mathrm{~mL}$ em um dia de coleta e a diferença de produção entre as colônias é devido á aptidão das abelhas coletar pólen. Em dias ensolarados, os coletores de pólen foram ativados das 09:46 ás 14:26, obtendo-se uma exelente produção, sem a necessidade de aplicar alimentação artificial.

Palavras-chave: pólen apícola, coleta de pólen, coleta de pólen não continua e bracatinga.
\end{abstract}

\begin{abstract}
In Mandirituba-PR, a city located in southern Brazil, the production of bee pollen in the top of Bracatinga's bloom was analyzed through the use of pollen collectors in non-continuous system for nine days from $3^{\text {rd }}$ to $23^{\text {rd }}$ August, 2005, the objective was to observe the time of the day that occurs the harvest by Apis mellifera connected to the ambient temperature and humidity. With this purpose were used 12 beehives of Africanized bees, with 9 mounth queens and stimulated with food only from bracatinga's bloom. The average production observed in the colonies was about $42,84 \pm 24,34 \mathrm{~mL}$ of bee pollen in a day of collection, and the difference of production between the beehives is due to the bee skills in collect pollen. In sunny days the pollen collectors were activated from 09:48 to $14: 26$ getting a great production without the necessity of implanting artificial food.
\end{abstract}

Key-words: bee pollen, non-continuous collectors, Bracatinga.

\footnotetext{
${ }^{1}$ Estudante de graduação do curso de Medicina Veterinária da Universidade Federal do Paraná;

${ }^{2}$ Engenheiro Agrônomo, Doutor, Professor, Departamento de Zootecnia, SCA - UFPR. 81531-990, Curitiba, PR.

E-mail: apegoraro@terra.com. br.
} 


\section{INTRODUÇÃO}

O pólen apícola é o produto obtido da aglutinação de diferentes grãos de pólen colhidos pelas abelhas e adição de suas secreções salivares e pequenas proporções de néctar, o que o torna diferente daqueles colhidos diretamente das plantas (MUNITAEGUl et al, 1993 apud VILLANUEVA et al, 2002).

Esse produto é utilizado na alimentação humana como um suplemento alimentar por conter substâncias essenciais como carboidratos, proteínas, aminoácidos, lipídios, vitaminas, minerais e traços de outras substâncias que podem compor a dieta da abelha mellífera, em função da vegetação presente na região, já que sua composição química e bioquímica é determinada pela origem vegetal (ESCRIBANO et al, 1999; KROYER e HEGEDUS, 2001). O pólen apresenta quantidades significativas de substâncias polifenólicas que podem variar de 7,4 a $9,7 \mathrm{mg} / \mathrm{g}$, principalmente de flavonóides que exercem um papel antioxidante inibindo a ação lesiva dos radicais livres, prevenindo, desta forma, diversas enfermidades que adviriam com essa lesão celular (KROYER e HEGEDUS, 2001).

O pólen também vem sendo utilizado no tratamento de prostatite, devido as propriedades anti-inflamatórias e efeito anti-androgênico, melhorar o desempenho de atletas devido a um efeito positivo no consumo de oxigênio e na recuperação pós-exercício, auxilia em problemas de memória e no tratamento de bronquite (GREENBERGER et al, 2001; SHOSKES e MANICKAM, 2003; ZORBA, 2003).

Nas amostras de pólen apícola coletado no sudoeste brasileiro foram encontrados $20 \pm 4 \%$ de proteína bruta; $6 \pm 2 \%$ de lipídios; $2,2 \pm 0,7 \%$ de minerais e outras substâncias não determinadas. Em dez amostras de pólen fresco coletado pela $A$. mellifera a média de carotenóides foi de $76,33 \mathrm{mg} / \mathrm{g}$ de pólen (ALMEIDA-MURADIAN at al., 2005). Em pólen apícola desidratado esses autores não encontraram Beta caroteno (provitamina A) e vitamina $C$ provavelmente por causa do processo de beneficiamento que utiliza alta temperatura de secagem.

A atividade de forragear pólen é um dos comportamentos mais importantes das colônias de A. mellifera. No entanto, deficiências no estoque ocorrem devidas à sazonalidade da oferta desse recurso alimentar (NABORS, 1997; PEGORARO, 1997).

Segundo Pankin e Page (2001) a quantidade de feromônio das larvas diminui em resposta à entrada de sacarose nas colônias. Os resultados obtidos por Dreller e Page (1999) sugerem que a atividade da $A$. mellifera forragear pólen está diretamente associada ao estoque de e a quantidade de larvas desta (na mesma). Então, a retirada de pólen por meio do coletor obriga as operárias forrageiras a coletar mais desse recurso e conseqüentemente menos néctar.

Em 1963, no início da africanização, na região de Araucária, no Paraná, os coletores de pólen não eram aceitos pela abelha africanizada. Porém, por meio de seleção com acasalamentos ao ar livre e retrocruzamentos com $A$. $m$. carnica esse comportamento mudou na abelha africanizada (KURLETTO, 1988).

Os objetivos desse trabalho foram avaliar o período do dia em que a abelha africanizada inicia e termina a coleta de pólen associada à temperatura ambiente e umidade relativa do ar, avaliar o potencial de produção de pólen durante a florada da Mimosa scabrella Benth em dias ensolarados e no período de sua disponibilidade e avaliar se as colônias são diferentes quanto a produção de pólen.

\section{METODOLOGIA}

A pesquisa foi realizada em um apiário localizado em Lagoa dos Ferreira, a $30 \mathrm{Km}$ da sede do Município de Mandirituba, situado na região sul do Brasil, no primeiro planalto do Paraná, longitude 4919'34" W, latitude 2519'44"S e altitude em torno de $840 \mathrm{~m}$. De acordo com o sistema de classificação climática de Köeppen, a região pertence ao clima Cfb, subtropical úmido, sem estação seca definida, com temperaturas médias do ano e dos meses mais frios e quentes, respectivamente, de $20^{\circ} \mathrm{C}, 13^{\circ} \mathrm{C}$ e $23^{\circ} \mathrm{C}$ e precipitação pluviométrica média anual de $1400 \mathrm{~mm}$ (IAPAR, 1994).

Neste experimento foram utilizadas 12 colônias de abelhas africanizadas pré-selecionadas, sendo que as rainhas possuíam a mesma idade (nove meses) e foram renovadas pelo método de desenvolvimento natural de realeiras, conforme Pegoraro et al. (1997). Não foi utilizada a alimentação artificial e os únicos alimentos fornecidos às colônias foram néctar e pólen, principalmente oriundos da florada de Bracatinga (Mimosa scabrella Benth.).

A coleta de pólen foi realizada somente em dias ensolarados com coletor de pólen que substituiu o fundo da colméia Langstroth e com tela descrita por Akatsu e Pegoraro (2001), em uso não continuo durante nove dias no intervalo de 03 a 23 de agosto de 2005. Nessa época, ocorreu, predominantemente, da florada de Bracatinga

No momento que as operárias forrageiras iniciavam a coleta de pólen foi marcado o horário e os coletores eram ativados. Já a temperatura e a umidade relativa no ar foram medidas conforme descrito em Pegoraro (2003). Quando a entrada de pólen nas colônias era finalizada os dados ambientais eram mensurados conforme descrito acima e os coletores de pólen eram desativados e a produção de pólen quantificada em $\mathrm{mL}$ em cada colônia.

Analisou-se a variável resposta: produção de pólen por colônia. Têm-se, então, um experimento, o qual está delineado em Blocos Inteiramente Casualizados. Para analisar variância dos dados da produção de pólen foi utilizada a Análise de variância (ANOVA) conforme (BOX et al., 1978). Para os cálculos estatísticos da média, desvio padrão e a ANOVA 
MOURA, J. E PEGORARO, A. Produção de pólen apícola com...

foi utilizado o aplicativo Statgraphics.

Testou-se a hipótese de igualdade das médias de produção de pólen entre as colônias, considerando que as mesmas são iguais, ou seja $\mathrm{H}_{01}: \grave{i}_{\mathrm{Ni}}=\grave{1}_{\mathrm{N}} \mathrm{i}=1$, $2, \ldots, a=12$ (médias da variável resposta produção de pólen diferente nos $\mathrm{a}=12$ níveis do fator colônia).

\section{RESULTADOS}

Os dados ambientais em relação ao inicio e final de coleta de pólen, na florada predominante de bracatinga, em dias ensolarados estão descritos na Tabela (1)

TABELA 1- Variáveis ambientais em dias ensolarados, no inicio e final da coleta de pólen de bracatinga, em nove dias, no período entre 03 a 23 de agosto de 2005, em Mandirituba, Paraná.

\begin{tabular}{|c|c|c|c|c|c|c|}
\hline Dias & Hic & Hfc & $\mathrm{T}^{\circ} \mathrm{Ci}$ & $T^{o} \mathrm{Cfc}$ & $U$ ic (\%) & $U f c(\%)$ \\
\hline 03/08/05 & 09:47 & $14: 31$ & 16,1 & 23,7 & 79 & 40 \\
\hline 04/08/05 & $09: 43$ & $14: 22$ & 16,7 & 23,5 & 76 & 42 \\
\hline 05/08/05 & 09:52 & $14: 48$ & 18,8 & 24,2 & 80 & 43 \\
\hline $15 / 08 / 05$ & 09:42 & $14: 43$ & 15,6 & 23,2 & 81 & 49 \\
\hline $16 / 08 / 05$ & $09: 57$ & $14: 11$ & 16,5 & 24,9 & 78 & 45 \\
\hline $17 / 08 / 05$ & $09: 43$ & $14: 04$ & 19,8 & 26,8 & 71 & 41 \\
\hline $18 / 08 / 05$ & $10: 14$ & $14: 03$ & 18,8 & 23,1 & 76 & 59 \\
\hline $22 / 08 / 05$ & 09:10 & $14: 04$ & 19,7 & 26,5 & 75 & 38 \\
\hline 23/08/05 & 09:11 & $14: 20$ & 19,9 & 27,4 & 70 & 34 \\
\hline Média & 09:48 & $14: 26$ & $17,99 \pm 1,74$ & $24,8 \pm 1,67$ & $77,22 \pm 3,8$ & $43,44 \pm 7,2$ \\
\hline
\end{tabular}

$\mathrm{Hic}=$ horário do inicio da coleta de pólen, $\mathrm{Hfc}=$ horário no final da coleta de pólen, $\mathrm{T}^{\circ} \mathrm{Ci}=$ temperatura em ${ }^{\circ} \mathrm{Celcius} \mathrm{no} \mathrm{inicia} \mathrm{da} \mathrm{coleta,}$

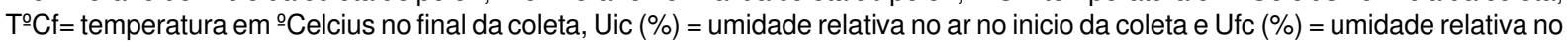
ar no final da coleta.

Os testes aplicados aos dados para saber se as premissas da Gaussianidade foram atendidas são Kolmogorov-Smirnov e Cochran. Os resultados estão apresentados nas Tabelas 2. A variável aleatória produção de pólen segue distribuição normal conforme
Tabela 2. A análise ANOVA demonstrou diferença estatisticamente significativa, observada através do valor $p=0,000$ (Tabela 2). Já entre os dias de coleta de pólen não existiu diferença estatisticamente significativa (Tabela 2).

TABELA 2 - Valores p dos testes para testar a Gaussianidade e homogeneidade de variância dos dados e análise de variância, no período entre 03 a 23 de agosto de 2005, em Mandirituba, Paraná.

\begin{tabular}{ccccc}
\hline $\begin{array}{c}\text { Tipo de } \\
\text { Alimento }\end{array}$ & Teste de Gaussianidade & Hom ogeneidade de & $\begin{array}{c}\text { Valor-p fator } \\
\text { principal }\end{array}$ & Valor-p fator (dias) \\
\hline Pólen & Kolmogorov-Smirnov & Cochran & ANOVA & AVOVA \\
\hline & $P=0,179$ & $P=0,113$ & $P=0,000$ & $P=0,575$ \\
\hline
\end{tabular}

Uma descrição dos dados da variável resposta produção de pólen com coletor de pólen em uso não continuo, no intervalo médio diário de 4:22 (quatro horas e $22 \mathrm{~min}$.) por dia de coleta
(Tabela 1 e 3) forneceu as seguintes estatísticas: $\mu=42,70 \pm 24,34 \mathrm{~mL}$ com mínimo de $3 \mathrm{~mL}$ de pólen e máximo de $120 \mathrm{~mL}$ de pólen (Tabela 3).

TABELA 3 - Média entre as colônias para a variável produção de pólen em doze colônias de abelha africanizada, no período de 03 a 23 de agosto de 2005, das 09:48 às 14:26, na florada da Bracatinga, em Mandirituba, Paraná.

\begin{tabular}{lcccccccccccc}
\hline Col. $^{*}$ & 9 & 11 & 4 & 12 & 2 & 1 & 10 & 6 & 3 & 7 & 5 \\
\hline $\mathrm{Pr}^{\star *}$ & 99,0 & 54,9 & 53,9 & 44,7 & 46,1 & 44,4 & 38,8 & 34,8 & 34,8 & 28,7 & 21,3 & 10,4
\end{tabular}

${ }^{*}$ Col = Número da colônia $\mathrm{pr}^{\star *}$ produção de pólen em $\mathrm{mL}$

\section{DISCUSSÃO}

A diferença estatisticamente significativa entre as colônias, mesmo que pré-selecionadas, de abelha africanizada quanto à aptidão das colônias coletarem pólen, estão em concordância com Allen e Jeffree (1956) que demonstram que colônias de $A$. mellifera coletaram em torno de $20 \mathrm{Kg}$ de pólen durante um ano e armazenaram (no momento de avaliação) em torno de $1 \mathrm{Kg}$ com variação de 119 a $3.296 \mathrm{~g}$ entre as colônias.
Buchmann et al. (1991) realizaram uma pesquisa no deserto do Arizona onde analisaram a capacidade da $A$. m. ligustica coletar pólen durante 34 semanas, o resultado obtido foi de uma média de $70,8 \pm 72,6 \mathrm{~g}$. Mesmo em ecossistemas e raças de abelhas diferentes a variabilidade da $A$. mellifera coletar pólen ficou caracterizada.

Os dados obtidos nesse trabalho reforçam a hipótese de que colônias de abelha africanizada são diferentes quanto á aptidão de coletar pólen e que é possível selecionar abelhas com essa aptidão 
MOURA, J. E PEGORARO, A. Produção de pólen apícola com...

(VENCOVSKI e KERR,1982; PEGORARO, 2003).

No entanto, entre os dias não existiu diferença estatisticamente significativa quanto á capacidade das colônias da abelha africanizada coletarem pólen (Tabela 2). Provavelmente porque foi coletado pólen somente em dias ensolarados e os dias foram semelhantes quanto ao tempo de coleta de pólen e condições de temperatura.

Utilizando coletor de pólen em uso continuo na florada de Bracatinga a produção média diária de pólen foi de ì = 42,84 \pm 24,34 $\mathrm{mL}$ (PEGORARO, 2003). Portanto, as médias de produção de pólen nos dois sistemas foram semelhantes. Provavelmente porque as condições em dias ensolarados foram mais favoráveis e compensaram o condicionamento das operárias forrageiras das colônias com coletor de pólen em uso contínuo (DRELLER e PAGE,1999).

Para Salomé (2000) colônias de abelha africanizada com coletores de pólen em uso continuo a produção de pólen aumentou $66,12 \%$ em relação àquela obtida quando o uso de coletor não foi contínuo. Em clima tropical com uso de coletor de pólen uma vez por semana no período de agosto a dezembro Funari et al. (1998) obtiveram produção média diária de pólen de 97,4 $\pm 40,5 \mathrm{~g}$. Essa diferença poderá ser atribuída, principalmente, a disponibilidade de alimento na natureza.

Por isso acreditamos que há necessidade de mais estudos quanto os métodos de coleta de pólen. Pois, a coleta do mesmo em abelha africanizada com coletor em uso continuo, durante 21 dias, reduz significativamente a quantidade de cria e alimento em colônia de abelha africanizada (PEGORARO, 2003)

\section{CONCLUSÕES}

Existe a possibilidade de coletar pólen de bracatinga nas colônias de abelha africanizada com coletor de pólen em uso não continuo e sem alimentação artificial com abelha africanizada na florada da bracatinga durante o mês de agosto;

$\mathrm{Na}$ florada da bracatinga os coletores de pólen podem ser ativados em dias ensolarados das 10:00 to $14: 30$.

\section{REFERÊNCIAS}

1. ALLEN, M.D.; JEFFREE, E. P. The influence of stored pollen and colony size on the brood rearing of honeybees. Ann. Appl. Biol., Warwick, v. 44, n. 4, p. 649-656, 1956.

2. ALMEIDA-MURADIAN, L. B.; PANPLONA, L. C.; COIMBRA. S. BARTH. O. M. Chemicalcomposition and botanical evaluation of dried bee pollen pellets. Journal of Food Composition and Analysis, São Paulo, v. 18, n.1, p. 105-111, 2005.

3. AKATSU. I. P.; PEGORARO, A. Largura do tórax de operárias de Apis mellifera scutellata Lepeletier, 1836 (Hym., : Apidae) e eficiência da tela coletora de pólen. Arch. Vet. Scinc., Curitiba, v. 6, n. 2, p. 77-82, 2001.

4. BOX, G. E. P.; HUNTER, W. G.; HUNTER, J. S. Statistics for experimenters, an introduction to design, data analysis, and model building. New York: John Wiley \& Sons, 1978. 537p.

5. BUCHMANN, S. L.; SHIPMAN, C. W.; PRCHAL, S. J. Phenology of pollen storage within honey bee colonies livin in the Sonoran desert of Arizona. Am. Bee J., Hamilton, p.772,1991.

6. DRELLER, C.; PAGE, R. E. Regulation of pollen foraging honeybee: effects of young brood, stored pollen, and empty space. Behav. Ecol. Sociobiol., Berlin, v. 45, n. 3, p. 227-233, 1999.

7. ESCRIBANO, A. M. L.; CARDENAL GALVAN, J. A.; ALVAREZ GOMES, J. A. ; POZO VERA, J. El polen controles sanitarios normas legales. Vida Api., Madri, v. 94, n. 2, p. 56-58, 1999.

8. FUNARI, S. R. C.; ROCHA, H. C. ; SFOCIN, J. M. ; CURI, P. R. ; PEROSA, J. M. Y. Coleta de pólen produção de mel e própolis em colônias de abelhas africanizadas (Apis mellifera L.). Bol. Ind. Anim., Nova Odessa, v. 55, n. 2, p. 189-193, 1998.

9. GREENBERGER, P. A.; FLAIS, M. D. MICHAEL, J. M.D. Bee pollen-induced anaphylactic reaction in an unknowingly sensitized subject Allergy, Asthma \& Immunology, Chicago, v.86, n. 2, p. 239-242, 2001.

10. IAPAR. Cartas climáticas do Estado do Paraná. Londrina, 1994.

11. KROYER, G.; HEGEDUS, N. Evaluation of bioactive properties of pollen extracts as functional dietary food supplement. Innovative Food Science \& Emerging Techologies, Vienna,v. 2 n. 3, p.171-174, 2001.

12. KURLETTO, S. Polinização dirigida In: SIMPÓSIO ESTADUAL DE APICULTURA DO PARANÁ, 3., 1989, Pitanga. Anais. Curitiba: A. Pegoraro, 1988. p. 2-16.

13. NABORS, R. Trapping pollen collections of the honey bee, Apis mellifera L. to determine pollen flow periods. Am. Bee. J., Hamilton, v. 137, n. 3, p. $418-425,1997$

14. PANKIN, T.; PAGE, R. E. Brood pheromone modulates honeybee (Apis mellifera L.) sucrose response thresholds. Behav. Ecol. Sociobiol., Berlin, v. 49, p. 206-213, 2001.

15. PEGORARO, A. Renovação de rainhas e desenvolvimento de colônias de Apis mellifera scutellata Lepeletier, 1836 (Hymenoptera, Apidae) infestadas naturalmente com Varroa jacobsoni Oudmans 1904. (Acari, Mesostigmata). Curitiba, 1997. 89.p. Dissertação (Mestrado em Ciências Biológicas), Universidade Federal do Paraná.

16. PEGORARO, A. Estudo da integração de diversos fatores no manejo de abelhas africanizadas Apis mellifera Linnaeus., 1758 (Himenóptera: Apidae), na unidade fitogeográfica da floresta com araucária, no sul do Brasil. Curitiba, 2003. 149. p. Tese (Doutorado em Agronomia), Universidade Federal do Paraná.

Recebido em 05/05/2006 Aceito em 28/09/2006 